University of Rhode Island

DigitalCommons@URI

Open Access Master's Theses

1973

\title{
The Effectiveness of Symptom and Dynamic Cues in the Systematic Desensitization of Test Anxiety
}

\author{
William A. Hancur \\ University of Rhode Island
}

Follow this and additional works at: https://digitalcommons.uri.edu/theses

\section{Recommended Citation}

Hancur, William A., "The Effectiveness of Symptom and Dynamic Cues in the Systematic Desensitization of Test Anxiety" (1973). Open Access Master's Theses. Paper 1627.

https://digitalcommons.uri.edu/theses/1627

This Thesis is brought to you for free and open access by DigitalCommons@URI. It has been accepted for inclusion in Open Access Master's Theses by an authorized administrator of DigitalCommons@URI. For more information, please contact digitalcommons-group@uri.edu. 
BF:

14

$1+40 \%$

THE FFFECTIVENESS OF SYMPTOM AND DYNAMIC CUES

II THE SYSTEMATIC DESENSITIZATION OF TEST ANXIETY

BY

UIILIAM A. HANCUR

A THESIS SUBMITTED IN DARTIAL FULFILLMENT OF THE

REQUIREMENTS FOR THE DEGREE OF

MASTER OF ARTS

IN

PSYCHOLOGY

JNIVERSITY OF RHODE ISLAND

1973 
ABSTRACT

This study purported to determine the effectiveness of symptom and aynamic cues in the systematic desensitization of test anxiety. It was hypothesized that both symptom and dynamic cues would be effective in reducing discuptive test anxiety and that dynamic desensitization would be superior to symptom desensitization in reducing general anxiety.

Twenty-two test anxious college males were randomly assigned to one of three treatment groups: 1) a symptom group treated with systematic desensitization based on cues related symptomatically to test anxiety; 2) a dynamic group desensitized with cues based on the underlying dynamics of test anxiety; or, 3) a no-treatment control group. Following four sessions of group desensitization, the symptom and dynamic groups reported significant reductions in anxiety on the Wolpe Fear Thermometer and Woipe rear Inventory. The dynamic group reported additional significant reductions on the Alpert-Haber Test Anxiety scale and the Wonderlic Personnel Test. The notreatmeit group reported no significant reductions in test anxiety across any of the measures. There was no differential anxiety reduction between the symptom and dynamic groups on any of the measures. These results indicate that systerlatic desensitization utilizing either symptom or dynamic aues is an effective treatment of disruptive 
test anxiety. They further suggest that dynamic desensitization may be superior to symptom desensitization alone and lend support to an integrative theory (Stampfl and Levis, 1967; Prochaska, 1970) which conceives of overall test anxiety as a combination of anxiety attached to both symptom and dynamic cues. 
This writer wishes to express his sincere appreciation to his Thesis Committee: Dr. James Prochaska, Chairman, Dr. Leila Cain and Dr. Richard Travisano for their generous and untiring assistance in the development and preparation of this thesis.

A special thanks is extended to Dr. Prochaska who has given of himself both as a co-experimenter and as a friend.

Finally, to my wife, Mary, whose love and encouragement make all things possible. 
TABLE OF CONTENTS

LIST OF TABLES

vi

INTRODUCTION

METHODOIOGY AND PROCEDURE 6

Subjects

Procedure

Dependent Measures

Treatment Conditions

RESULTS

$\begin{array}{ll}\text { DISCUSSION } & 18\end{array}$

REFERENCES 2$].$

$\begin{array}{ll}\text { APPENDIX } & 24\end{array}$ 


\section{LIST OF TABLES}

Table

Page

1. Medians and Wilcoxon analysis of difference between before and after treatment scores for symptom, dynamic and control groups across all measures.

2. Kolmogorov-Smirnov analysis of change score data comparing symptom and dynamic groups across all measures. 


\section{INTRODUCTION}

Psychotherapists of all persuasions are constantly seeking better and more efficient methods of effecting behavioral change. Traditional therapies, like psychoanalysis, have stressed the dynamic forces that are assumed to underlie observable behavior, while certain contemporary therapies have focused upon specific symptoms to the virtual exclusion of dynamic factors (Wolpe, salter \& Reyna, 1964). Some attempts have been made to bridge the gap between these conflicting systems. Alexander \& French (1946) indicate the futility of insight per se as the mecharism of therapeutic change and advise the analyst to become actively engaged in the patient's life outside the therapy hour, even to the point of being directive, as a necessary conclusion to the uncovering experience. Frankl's logotherapy (1959) pays attention both to the observable symptom and to the patient's attitude toward himself and his symptom. Successful integrative attempts have been made by behavior therapists, like stampfl and Levis (1967) who have drawn heavily upon dynamic material in thein implosive technique.

While these attempts have added significantly to our thinking about psychotherapy, only Prochaska (1970) has actualy investigated the relative effectiveness of dynamic and symptom cues in an empirical study. In the inplosive treatment of test anxiety, he was able to 
demcnstrate that scenes based exclusively on dynamic material i.e. repressed thoughts and impulses which grow out of past experiences and relationships, were just as effective as those based on symptoms i.e. fears which are attached to environmental stimuli in the present. Test anxiety is an appropriate symptom for study since a well-articulated dynamic base has been hypothesized by Sarason et al. (1960). In their formulation, test anxiety is regarded as resulting from the student's transference of certain conflicts with his parents into his relationship with his teachers. They hypothesize that prior to school the high test anxious child has been negatively evaluated by his parents. The child is frustrated and angered by this evaluation but he is afraid to express this anger out of fear -- fear of retaliation by his Iather and fear of losing the love and affection of his parents. In test situations, the student reacts to his teacher as if he were his parent and to the test situation as if it were his parent's means of evaluating him. His anger over such evaluation is aroused but so is his fear of retaliation and loss of affection. It is this fear that the student experiences as test anxiety. While Prochaska's study (1970) on test anxiety is an inportant first step, its real value lies more in the questions it raises than in the answers it provides. The neel for continued work along the same lines, but utilizing other therapeutic moàels, is obvious to the 
practicing clinician who may find implosive therapy contraindicated in some instances. Systematic desensitization, in which anxiety to a given set of stimuli is reduced by presentation of the stimuli to the patient while he is deeply relaxed, provides another model which can use both dynanic and symptom cues. The effectiveness of this procedure using symptom cues to treat anxiety has been clearly established by investigators using a wide variety of performance and self-report measures (Emery, 1967; Kondas, 1967 ; Emery \& Krumboltz, 1967 ; Jonnson \& Sechrest, 1968; Suinn, 1968; Garlington \& Cotler, 1968; Donner \& Guerney, 1969; Crighton \& Jehu, 1969 ; Cohen, 1969; and Freeling \& Shemberg, 1970). Systematic desensitization with dynamically based hierarchies has recently been used by Feather and Rhoads (1972) who report successful case studies of some obsessivecompusive disorders. Beyond these few case reports, however, no empirical studies using dynamic cues have been reported.

The present study proposes to determine the effectiveness of dynamic and symptom cues in the systematic desansitization of test anxiety in an effort to extend Prochaska's work (1970) and to possibly provide the clinician with another viable therapeutic option in the treatment of this disorder. Further, if the systematic desensitization of test anxiety using dynamic cues can be demonstrated to be effective: this would challenge the 
general theoretical assumption of Wolpe (1958; 1969) et al. that symptoms are strictly the result of anxiety being conditioned to environmental stimuli with hypothesized dynamic stimuli being considered irrelevant either to symptom proauction or to symptom removal. Working from Stampfl and Levis' (1967) more integrative theory of symptom production which considers both symptom and dynamic cues to be relevant factors, it is hypothesized that systematic desensitization with both symptom and dynamic cues will produce significant reductions in test anxiety and that there will be no significant reductior with no treatment. Furthermore, if sarason's (1960) dynanic formulation is accurate, as Prochaska's (1970) study suggests, it is hypothesized that systematic desensitization with dynamic cues will result in a Ereater reobution of general anxiety than with symptom cues alone, due to Ereater generalization of anxiety reduction extending to other, apparently diverse situations ir which the high test anxious student finds himself.

If these hypotheses ars supported, then it would cause theorists and researehers in systematic desensitization to consider dynamic cues as relevant factors both in the eijology and treatment of test anxiety. Such a inaing would have important implications for further research into the relationship between symptoms and underlying dynamics, especially in response to the theories 
of Wolpe (1958; 1969) and Eysenck (1959) who regard symptoms as unrelated to underlying dynamics. 


\section{METHODOLOGY AND PROCEDURE}

\section{Subjects}

E announced in large lecture classes that he was conducting a study with a new therapy that is intended to reduce disrupting test anxiety. The study was described as presently being limited to men who met the fol.lowing criteria; a) report high levels of anxiety on tests; b) believe that this anxiety interferes with test performance; and c) are willing to volunteer six hours of their time during the remainder of the semester. of those students who met these pre-selection criteria, only those who scored approximately one standard deviation higher on the Alpert-Haber Test Anxiety Scale than the average for the total sample in the original Alpert and Haber (1961) study were included in the experiment. The average score for all Ss was 66.36 out cf a posible 95 points, as compared to a mean of 44.05 in the Alpert and Haber (1961) study.

Thirty-four test anxious males were pretested and then randomly assigned to either a symptom desensitization $(n=1.2)$, dynamic desensitization $(n=12)$ or notreatment group $(n=10)$. Four ss were lost from each group leaving a total sample of twenty-two. One $\underline{S}$ in the dynamic group was unable to learn deep muscle relaxation and was treated individually. His data were then dropped from the study. One S from each treatment group was lost prior to the first treatment session. Three Ss from the 
symptom group, two $\underline{S}$ from the dynamic group and four $\underline{S}$ from the control group failed to return for post-testing. Dependent Measures

Alpert-Haber Test Anxiety Scale. The same form of this test was administered twice and all nineteen items in this scale were scored for debilitating test anxiety. This scale was chosen because of its ability to differentiate debilitative from facilitative test anxiety, (Alpert and Haber, 1961), thereby identifying a less confounded group of $\underline{S}$. Effective treatment of test anxiety was expected to result in significantly lowered scores for the symptom and dynamic desensitization groups but not in the no-treatment group.

Worderlic Personnel Test. Forms $A$ and $V$ were used since Wonderlic (1961) reports them to be comparable. The test was introduced as an intelligence scale that was designed to test the $\underline{S}^{\prime} s$ intellectual ability. The standard twelve minute time limit was used. This test was assumed to be a paradigm of testing situations in which the disrupting effects of test anxiety should result in lowered performance due to the somewhat threatening nature of the evaluation i.e. intelligence and the pressure of a time Iimit. This test was used successfully by Prochaska (1970) as a measure of reduction in disruptive test anxiety. Effective treatment of test anxiety was expected to result in higher scores for the symptom and dynamic desensitization groups, but not in the no-treatment group. 
Wolpe Fear Thermometer. This is a 100 point scale with zero representing the most relaxed a person has ever felt and 100 representing the most anious. This scale was used as a self-report anxiety measure after administration of the Wonderlic Personnel Test with $\underline{\text { S }}$ being asked to rate how anxious they were while taking the test. This scale has been used successfully by Prochaska (1970) with test anxiety and by Wolpe (1958) with a variety of fear situations. Effective treatment of test anxiety was expected to result in lower scores for the symptom and dynamic desensitization groups but not in the notreatment group.

Woloe Fear Inventory. The same form of this test was given twice. Ss were instructed to rate how anxious they felt in the presence of these situations or objects e.g. snakes, being ignored, airplanes, etc., on a five point scale ranging from Not at All (scored zero) to Very Much (scored four). This scale was used to measure generalization of treatment to other fear situations or objects. Dynamic theories, as opposed to symptom-specific theories, would predict generalization from one symptom group to another if the underlying dynamic conflicts have been resolved. From this viewpoint, it was therefore expected that $\in$ ffective treatment of test anxiety with dynamic desensitization should result in greater generalization i.e. Iower scores, as compared to the symptom desensitization group. 


\section{Treatment Conditions}

Symptom Desensitization. The following sixteen item hierarchy is identical to that used by Emery \& Krumboltz (1967) and contains many items used by Prochaska (1970) in his implosive scenes. The order of presentation was standardized as follows:

1. The teacher announces and discusses a course examination (to be held in three weeks) with the class.

2. Studying for an important examination that is two weeks away.

3. Studying for an important examination that is one week away.

4. Studying for an important examination that is two days away.

5. Studying for an important examination that is the next day.

6. Discussing an important examination with friends the night before the exam.

7. Going to sleep the night before the important examination.

8. It is the day of the examination -- one hour left until exam time.

9. Leaving your room at your living gliarters to go to the important examination.

10. Entering the room where the examination is being given and sitting down.

11. The examination is being handed out -- you receive a copy.

12. Reading over the instructions to the important examination and surveying the test.

13. Taking the jmportant examination and working on a question to which you know the answer.

14. Taking the important examination and working on a question to which you do not know the answer. 
15. While trying to think of an answer to an examination question, you notice everyone around you writing very rapidly.

16. Having thirty minutes left to complete the examination and an hour's worth of work to do.

Dynamic Desensitization. The following sixteen item hierarchy is based theoretically on Sarason's (1960) dynamic hypothesis of text anxiety and empirically on Prochaska's (1970) study, which found them to be effective in reaucing disruptive test anxiety via implosive therapy. The order of presentation was standardized as follows:

1. You rave to paint the living room of your hone.

2. While painting, you spill a little paint on the rug.

3. Your parents are criticizing you for the paint on the rug.

4. Your parents are harping about how stupid you are.

5. You are feeling angry at your parents over their criticizing you.

6. You are cussing your parents out over their getting on your back.

7. You are telling your parents to get off your back.

8. Your father is telling you to shut your mouth and to mind your manners.

9. Your father is slapping your face because you cussed him out.

10. Your father knocks you down to the ground.

1.. Your father stomps on your midale finger.

12. Your father kicks you in the groin.

13. Your father pulls your pants down and stomps on your penis. 
14. Your father is cutting your peris off with a $\mathrm{knife}$.

15. Your parents are telling you to pack your bags.

16. Your parents are telling you to get out of the house and stay out.

These cues are ordered according to their assumed ability to elicit anxiety - from criticism through physical abuse to loss of affection. The rationale for this order is provided by Sarason's (1960) dynamic theory of test anxiety. No Treatment. This was a no-contact control group. Other Controls. Placebo controls, such as relaxation, unrelated dynamic and general anxiety groups were considered unnecessary in light of Davison's (1968) study which found no significant improvement for pseudo-counterconditioning and unrelated imagery controls in the aesensitization of snake phobias. Prochaska (1970) has reported similar results with implosive therapy. Additionaily, Johnson \& Sechrest (1968) report no significant difference between relaxation and no-treatment groups in the desensitization of test anxiety.

Procedure

Pretesting was completed in one session with the tests being presented in the following order: Wonderlic Personnel Test (Form $A$ ), Wolpe Fear Thermometer, Alpert-Haber Test Anxiety Scdle and Wolpe Fear Inventory. Between pretesting and the first therapy session, Ss assigned to treatment groups were informed of their appointment times. The notreatment group was told that the facilities were full at 
the present time and that they wouid be contacted at a later time when there was room available for treatment. (Treatment was, in fact, offered to this group after posttesting was completed.) Each of the two treatment groups was divided into four sections $(n=3)$. Two therapists, one an advanced clinical psychology graduate student and one a Ph.D. clinical psychologist, both trained in systematic desensitization, conducted the treatment, each having two sections in each treatment group. Group desensitization with standardized hierarchies was used in accordance with the methods employed successfully by IhIi \& Garlington (1969), Paul \& Shannon (1966) and Lazarus (1961), with $\underline{\text { Ss }}$ being taught deep muscle relaxation in the first hourly session followed by three hourly sessions of systematic desensitization. Besides using group desensitization ard standardized hierarchies, the therapy followed Wolpe's (1958; 1969) original procedure including instructing $\underline{S}$ to practice relaxation between the weekly treatment sessions. The treatment proceeded until all items in the hierarchy had been presented and continued until the entire hierarchy coula be presented without any $\underline{S}$ signaling anxiety. Groups who achieved this criterion prior to the end of the third aesensjtization session began the hierarchy a second time. Upon corpletion of treatment, all remaining $\underline{S}$ s and the notreatment controls were again tested with the Wonderlic Persomel Test (Form V), followed by the Wolpe Fear Thermometer, Alpert-Haber Test Anxiety Scale and the Wolpe Fear 
Inventory. These were given in the same order as in pretesting. The entire procedure took six weeks with one week intervals between pretesting and treatment, and treatment and post-testing. 


\section{RESULTS}

Nonparametric statistical analyses were employed since the level of measurement was ordinal, the sample size was very smal. $(n=8)$ and sketches of the distributions showed them to be non-normal. The choice of the analysis is well supported by Bradley (1960, 1968) who states that, when sample size is small ( $\leq \leqslant 10)$, violations of parametric assunptions have tineir most devastating effect and yet are least likely to be detected. Therefore, nonparametric tests are considered the analyses of choice in this study. Hypothesis I stated that there would be significant raductions in test enxiety for the symptom and dynamic groups as measured by the Alpert-Haber Test Anxiety Scale (A-H), Wolpe Fear Thermometer (WT), Wolpe Fear Inventory (WI) and Wonderlic Personnel Test (WP). No significant redictions were predicted for the no-treatment group. Ditiference between before and after treatment scores for ach group were analyzed by means of the Wilcoxon MatchedPairs Signed-Ranks Test. These data, as well as group medians are found in Table 1. Raw dat, a can be found in the Appendix. 


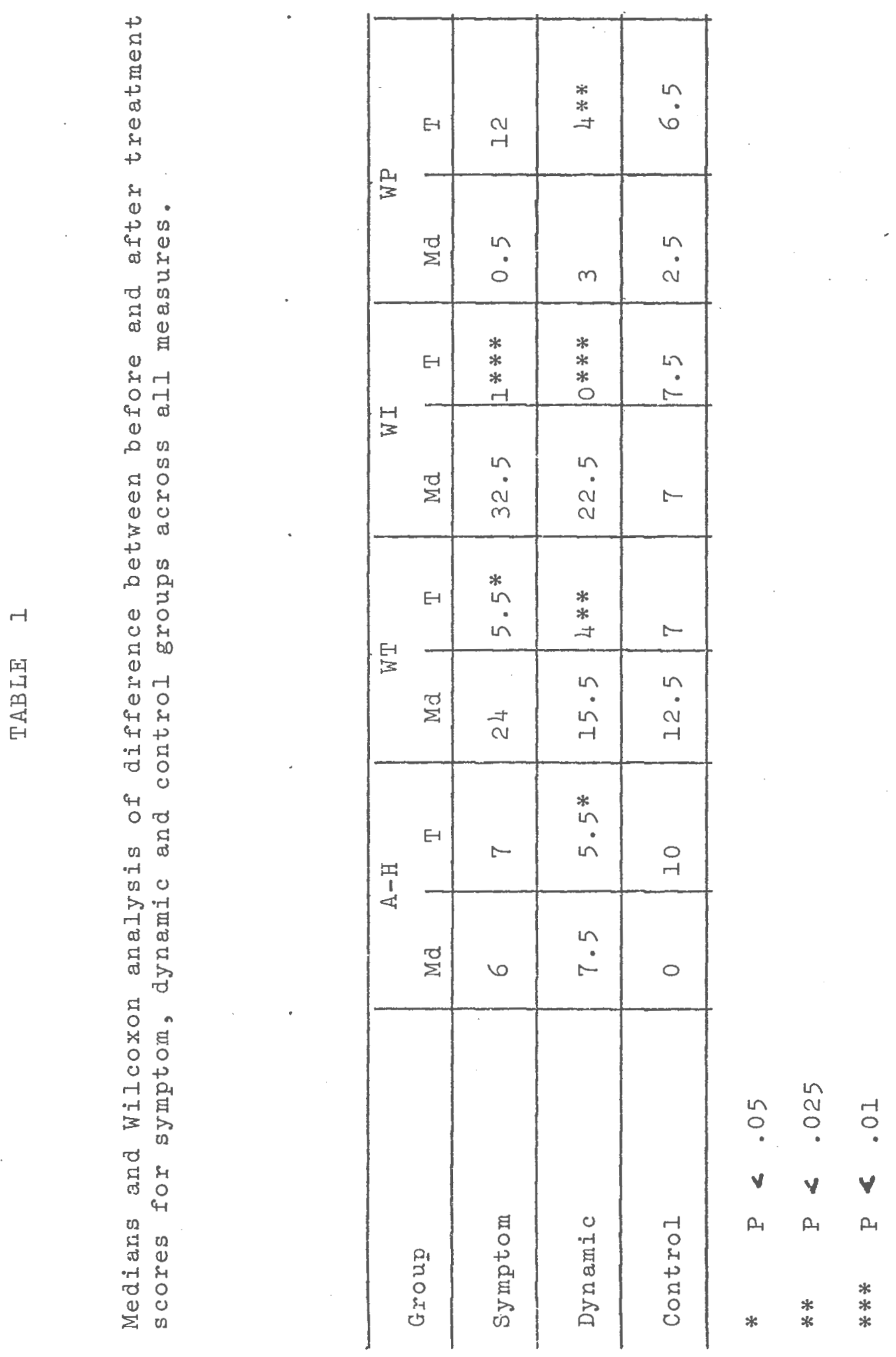


As Table I shows, data analysis of the Alpert-Haber Test Anxiety Scale yielded significant results in the predicted direction for the dynamic group ( $<<.05)$. Analysis of the Wolpe Fear Thermometer and Wolpe Fear Inventcry yielded significant results for the symptom group $(P<.05$ and $P<.01)$ and for the dynamic group $(P<.025$ and $P<.01)$. Analysis of the Wonderlic Personnel Test yielded a significant result for the dynamic group only $(P<.025)$. No significant results were found for the no-treatment group on any of the measures.

Hypothesis II predicted that the dynamic group would show a greater reduction in general anxiety than the syintom group as measured by the Wolpe Fear Inventory. It was expected that there would be no significant difference between the symptom and dynamic groups for differential anxiety reduction on the other three measures. These data were analyzed by means of the Kolmogorov-Smirnov Two-Sample Test since this test is sensitive to differences in location, ãispersion and skewness (Siegel, 1956). Table 2 reports this analysis.

\section{TABLE 2}

Kolmogorov-Smirnov analysis of change score data comparing symptom and dynamic groups across all measures.

\begin{tabular}{l|c|c} 
Measure & $K_{D}$ & 0 \\
\hline$A-H$ & 1 & $>.20$ \\
\hline MT & 2 & $>.20$ \\
\hline WI & 4 & $.11-.20$ \\
\hline WP & 4 & $.11-.20$ \\
\hline
\end{tabular}


The results of this test indicate that there was no significant difference between the change scores of the symptom and dynamic groups on any of the measures $(P>.05)$. 


\section{DIS CUSSION}

This experiment purported to study the effectiveness of symptom and dynamic cues in the systematic desensitization of test anxiety. The primary hypothesis stated that both symptom and dynamic cues would be effective in reducing dis.ruptive test anxiety. A second hypothesis predicted that dynamic desensitization would result in a Exater reduction of general anxiety as determined by the Wolpe Fear Inventory, than would symptom desensitization. The data indicate that both symptom and dynamic desensitization are effective in reducing test anxiety but that neither symptom nor dynamic desensitization is superior in anxiety reduction across any of the measures.

A closer examination of the data reveals that only dynamic desensitization effected a significant change on the Alpert-Haber Test Anxiety Scale, although the symptom group did attain change at $P<.07$. This pattern was repeated on the Wolpe Fear Thermometer and also on the Wonderlic Personnel Test in which the dynamic group achiaved greater degrees of statistical significance thar did the symptcm group. Both groups attained the same leveis of probability on the Wolpe Fear Inventory.

While these results are consistent with the dyramic theory cf test anxiety postulated by sarason et al. (1960) and the symptom sqecific theories of Emery and Krumboltz (1967) and Kondas (1967), neither theory accounts for anxiety reauction in both the symptom and dynamic groups. 
Support is provided for an integrative theory (stampfl and Levis, 1967; Prochaska, 1970) which conceives of overall test anxiety as a combination of anxiety elicited by both symptom and dynamic cues. Thus, as predicted from this theory, a reduction in anxiety to either symptom or dynamic cues leads to a significant reduction in test anxiety.

The consistency of dynamically-oriented desensitization across these measures suggests that it may be more effective than symptom desensitization in reducing test anxiety. This differential change effect between symptom and aynamic desensitization was not able to be demonstrated statistically in this study, probably due to the restrictions of small sample size: Since the issue of the effectiveness of symptom and dynamic cues has importart psychotnerapeutic implications, large differences were needed in order to justify practical conclusions. Therefore, small samples were able to test these large effects. Differential change, however, has important theoretical implications. This study suggests that Iarger samples may be needed in order to test these more statistically subtle, theoretical questions. A prediction chat aynamic desensitization is more effective than symptom desensitization in reducing test anxiety may be made in extended research based upon the results of this study. The sact that dynamic desensitization was shown to be an effective treatment of disruptive test anxiety 
thrusts open the door to further empirical investigation into dynamically-oriented systematic desensitization utilizing both symptom and dynamic cues and serves to add support to the work of Prochaska (1970) and Stampfl and Iuevis (1967) who postulate a dynamic base to behavioral symptoms. It also stands as a strong challenge to Wolpe (1958; 1969) and Eysenck (1959) who consider dynamic factors to be irrelevant to either symptom production or removal. If such dynamically-oriented behavior therapy car be shown to be more effective than symptom treatment alone, it would help to bridge the existing rift between traditional psychotherapists and strict behaviorists by providing therapeutic instruments which encompass both theoretical positions. 
Alexander, F. \& French, T. Fsychoanalytic Therapy. New York: Ronald Press, 1946.

Alpert, R. \& Faber, R. Anxiety in academic achievement, situations. J. of Abnormal and Social Psych, 1960, $\underline{66}, 207-216$.

Bradley, J. Distribution-free statistical tests. Englewood Cliffs, New Jersey: Prentice-Hall, Inc., 1968.

Bradley, J. Distribution-free statistical tests. Ohio: Wright-Patterson AFB, 1960.

Coher, R. The effects of group interaction and progressive hierarchy presentation on desensitization of test anxiety. Beh. Res. and Therapy, 1969, 1, 15-26

Crighton, J. \& Jehu, D. Treatment of examination anxiety by systematic desensitization or psychotherapy in groups. Beh. Res. and Therapy, 1969, I, 245-248.

Davison, G. Systernatic desensitization as a counterconditioning process. J. of Abnormal Psych., 1968, 73, 91-99.

Donner, L. \& Guerrey, B. Automated group desensitization for test arxiety. Beh. Pes. and Therapy, 1969, I, $1-14$

Emery, J. Evaluation of standard versus individualized hierarchies in desensitization to reduce test anxiety. Dissertation Abstracts, 1967, 27, $2510-2511$

Enery, J. \& Krumboltz, J. Standard versus individualized hiensrchies in desensitization to reduce test anxiety. J. of Counseling Psych., 1967, 14, 204-209

Eysenck, $\mathrm{I}$. Learning theory and behavior therapy. in Millon, T. (ed.) Theories of Psychopathology, Phila.: W. B. Saunders Co., 1967, 388-402

Festher, B. \& Rhoads, J. Psychodynamic Behavior Therapy. Arch. Gen. Psychiat., 1972, 26, 503-511.

Frankl, V. Mar's search for meanirg. New York: Simon ard Schuster, 1959.

Freeling, N. \& Shemberg, K. The alleviation of test anxiety by systenatic desensitization. Beh. Res. and Therapy, $2970,8,293-300$. 
Garlington, $W$. \& Cotler, S. Systematic desensitization of test anxiety. Beh. Res. and Therapy, 1968, 6, $247-256$.

Ihli, K. \& Garlington, W. A comparison of group versus individual desensitization of test anxiety. Beh. Res. and Therapy, 1969, I, 207-210.

Johnson, S. \& Sechrest, L. Comparison of desensitization and progressive relaxation in treating test anxiety. J. of Counseling and Clinical Psych., 1968, 32, 280-286.

Kondas, L. Reduction of exam anxiety and stage fright by group desersitization and relaxation. Beh. Res. and Therapy, 1967, 5, 275-281.

Lazarus, A. Group therapy of phobic disorders by systematic desensitization. J. of Abnormal and Social Psychology, $1961,63,504-510$.

Paul, G. \& Shanron, D. Treatment of anxiety through systematic desensitization of therapy groups. J. of Abnormal Psych., 1966, 71, 124-135.

Prochaska, J. Symptom and dynamic cues in the implosive treatment of test anxiety. J. of Abnormal Psych., $1971,77,133-142$.

Sarason, S., Davidson, K., Lighthall, F., Raite, R. \& Ruebush, B. Anxiety in elementary school children. New York: John Wiley, 1960.

Siegel, S. Non-parametric statistics: for the behavioral sciences. New York: McGraw-Hill Book Co., Inc., 1956.

Stampfl, T. \& Levis, D. Essentials of implosive therapy: a learning-theory-based psychodynamic behavioral therapy. J. of Abrormal Psych., 1967, I2, 496-503.

Suinn, R. The desensitization of test anxiety by group and individual treatment. Beh. Res. and Therapy, $1968, \underline{6}, 385-387$.

Winer, B. Statistjcal principles in experimental design. New York: McGraw-Hill Book Co., Inc., 1962.

Wolpe, J. Psychotherapy by reciprocal inhibition. St anford: Stanford University Fress, 1958.

Wolpe, T. The practice of behavior therapy. New York: Perganon Press, Inc., 1969.

Wolpe, J., Salter, A. \& Reyna, J. The conditioning therapies: the challenge in psychotherapy. New York: Holt, Pinehart \& Winston, 1964 . 
Wonderlic, E. Performance norms by adults on separate form of the wonderlic personnel tests. Northfield, Illinois: E.F. Wonderlic \& Associates, Inc., 1961. 
APPENDIX 
Raw Data: Pre-test

\begin{tabular}{|c|c|c|c|c|c|}
\hline & $\underline{\mathbf{S}}$ & $A-H$ & $\mathrm{WT}$ & WI & WP \\
\hline $\begin{array}{l}\text { Symptom } \\
\text { group }\end{array}$ & $\begin{array}{l}1 \\
2 \\
3 \\
4 \\
5 \\
6 \\
7 \\
8\end{array}$ & $\begin{array}{l}59 \\
64 \\
59 \\
73 \\
85 \\
83 \\
59 \\
62\end{array}$ & $\begin{array}{l}32 \\
60 \\
46 \\
50 \\
60 \\
30 \\
20 \\
70\end{array}$ & $\begin{array}{r}102 \\
89 \\
96 \\
123 \\
114 \\
98 \\
91 \\
147\end{array}$ & $\begin{array}{l}28 \\
30 \\
39 \\
26 \\
28 \\
18 \\
36 \\
30\end{array}$ \\
\hline $\begin{array}{r}\text { Dynamic } \\
\text { group }\end{array}$ & $\begin{array}{l}1 \\
2 \\
3 \\
4 \\
5 \\
6 \\
7 \\
8\end{array}$ & $\begin{array}{l}51 \\
59 \\
78 \\
61 \\
75 \\
85 \\
83 \\
44\end{array}$ & $\begin{array}{l}60 \\
50 \\
70 \\
30 \\
59 \\
50 \\
45 \\
80\end{array}$ & $\begin{array}{r}161 \\
140 \\
119 \\
94 \\
107 \\
114 \\
91 \\
154\end{array}$ & $\begin{array}{l}23 \\
25 \\
23 \\
31 \\
37 \\
27 \\
30 \\
29\end{array}$ \\
\hline $\begin{array}{l}\text { No-treatment } \\
\text { group }\end{array}$ & $\begin{array}{l}1 \\
2 \\
3 \\
4 \\
5 \\
6\end{array}$ & $\begin{array}{l}80 \\
50 \\
48 \\
64 \\
68 \\
70\end{array}$ & $\begin{array}{l}30 \\
10 \\
50 \\
75 \\
80 \\
80\end{array}$ & $\begin{array}{r}117 \\
93 \\
114 \\
123 \\
88 \\
119\end{array}$ & $\begin{array}{l}28 \\
28 \\
31 \\
33 \\
18 \\
32\end{array}$ \\
\hline
\end{tabular}


Raw Data: Post-test

$\begin{array}{rrrrrr} & \text { S } & \text { A-H } & \text { WT } & \text { WI } & \text { WP } \\ \text { Symptom } & I & 65 & 14 & 68 & 25 \\ \text { group } & 2 & 67 & 10 & 58 & 30 \\ & 3 & 50 & 10 & 69 & 37 \\ & 4 & 68 & 40 & 87 & 27 \\ & 5 & 65 & 9 & 65 & 27 \\ & 6 & 73 & 50 & 121 & 26 \\ & 7 & 52 & 30 & 65 & 33 \\ & 8 & 66 & 40 & .103 & 32\end{array}$

$\begin{array}{crrrrr}\text { Dynamic } & 1 & 42 & 40 & 50 & 27 \\ \text { group } & 2 & 63 & 10 & 131 & 29 \\ & 3 & 74 & 59 & 91 & 29 \\ & 4 & 55 & 10 & 38 & 33 \\ & 5 & 62 & 60 & 90 & 39 \\ & 6 & 76 & 60 & 110 & 28 \\ & 7 & 74 & 40 & 75 & 43 \\ & 8 & 52 & 12 & 83 & 26 \\ \text { No-treatment } & 1 & & & & \\ \text { group } & 2 & 42 & 30 & 111 & 32 \\ & 3 & 50 & 20 & 101 & 33 \\ & 4 & 66 & 70 & 135 & 36 \\ & 5 & 66 & 40 & 98 & 22 \\ & 6 & 65 & 60 & 107 & 28\end{array}$

